\title{
DETERMINING THE STRENGTH OF INDUSTRIAL GROUPING METHODS
}

\author{
Anthony L. Loviscek and Chin-Wei Yang*
}

\section{Introduction}

In a comprehensive study, Czamanski and Q. Ablas (1979) reviewed the properties of and the results generated by seven methods that produce spatial and aspatial industrial groups. Such a group, often referred to as a "complex" or a "cluster," can be defined as a set of industries set apart from other industries by strong interindustrial transactions. In particular, the transactions, or linkages, are stronger within the group than outside of it. The linkages, both demand- and supplyconstrained, are usually taken from cross sectional measurements of linear production structures and linear sales patterns used in input-output economics. The reason for using grouping methods is to expose structural characteristics (industrial groups) that are neither obvious nor detectable by visual examination of input-output transactions. Although the evidence might be casual, some feel that these characteristics provide valuable information on the nature of regional and urban economic activity (e.g., Streit, 1969; Campbell, 1975; Mattila and Tybout, 1977; Harrigan, 1982; and O'hUallachain, 1984). Specifically, industrial groups are thought to play a pivotal role in Hirschman-type development strategies, in the formation of agglomeration economies, and in monitoring changes in economic bases.

There are three questions that the literature has not addressed. First, as Czamanski and Q. Ablas have shown, there are many grouping methods available. These methods are also diverse because they involve variations on principal components analysis, graph theory, network analysis, and triangularization of matrices. ${ }^{1}$ Complicating matters is that the results can vary significantly across methods (Masser and Scheurwater, 1980; and Loviscek, 1984). Therefore, on what grounds do analysts

- The authors are Associate Professors of Economics at, respectively, Indiana University-Purdue University at Fort Wayne and Clarion University. choose one method over another? Second, and following from the first question, which method(s) should analysts use? Third, analysts (e.g., Czamanski and Czamanski, 1977) have mentioned the appeal of using industrial groups as part of a regional development strategy. To what extent can and should industrial groups be used as a policy tool in such strategies? The present study is concerned with the first question. Specifically, the study proposes three criteria to help analysts narrow the range of choice among methods. Moreover, we contend that the first question must be answered before moving to the next two. This is obvious in the case of the second question. As evidence that this should be so in the case of the third question, note the study of Yotopoulos and Nugent (1973). They tested the Hirschman linkage hypothesis on unbalanced growth discussed in the literature on economic development. They used what they called a "total linkage" measure, which is the column sum for each industry in the Leontief inverse. They used aggregated input-output data for 11 countries and concluded that Hirschman's hypothesis did not hold. Their study brought forth critical comments, which dealt principally with the use of the total linkage measure (Laumas, 1976; Boucher, 1976; Riedel, 1976; and Jones, 1976). Each of the authors demonstrated that the test gave misleading results because the total linkage measure for industry $j$ does not accurately account for all of its interindustry effects. The point is one that analysts of such studies know well-the results can be very sensitive to the choice of tool. The same is true in studies that deal with industrial groups. For instance, using industrial groups as part of a test of a regional growth theory hinges on the composition of the groups, which, as pointed out, can vary across the diverse methods.

By what criteria should analysts choose among methods? This is not a trivial question. Presently, in addition to the seven methods examined by Czamanski and Q. Ablas, analysts can choose from among at least five others: 
Lodh and Lewis (1975); Masser and Brown (1975); Blin and Cohen (1978); Slater (1977); and Harrigan (1982). However, analysts do not have criteria to help them decide which of the methods produces acceptable industrial groups, that is, groups that accurately reflect the production structures and sales patterns of an area. ${ }^{2}$ Specifically, the use of such criteria could help them determine the strengths and weaknesses of a method. In particular, once the weakness(es) is (are) found, analysts can then see how modifications to correct the weakness affect the composition of the groups. By finding acceptable industrial groups analysts can: 1) improve the reliability of research that involves the use of industrial groups, and 2) increase the chance that a development strategy that uses such groups will work. ${ }^{3}$ Moreover, it is impossible to propose a new and, presumably, better technique without knowing how well each of the existing methods works.

Although there are at least 12 methods for producing industrial groups, there are several technical issues that policy analysts need to understand. The issues will be discussed within the context of the present study. First, the grouping methods are part of "exploratory data analysis," a "loose" body of applied statistics based on inductive inquiry." This leads to two limitations: 1) inferences must be made from the results without the aid of theory, and 2) there are neither mathematical nor statistical $a$ priori guidelines about what is an acceptable industrial group. Simply put, conventional statistics (e.g., "t $t$ " and "F" tests), with few exceptions, cannot be used to determine which industries are members of an industrial group. ${ }^{6}$ Consequently, considerable judgment-perhaps more than some analysts prefer-must be used to determine the composition of a group.

Second, the present study is concerned with the application of grouping methods to inputoutput tables. Although most of the work on industrial groups so far has relied on inputoutput data, these data may be neither necessary nor sufficient for understanding how industrial groups form or how they can be used for policy. As evidence, Bergsman, Greenston, and Healy (1972) did not use input-output data in their study of industrial groups for 203 Standard Metropolitan Statistical Areas. One important point implied in their study is that several industries can form an industrial group solely by being located closely to each other; none buys anything from the other. By definition, such a group is not an industrial group because it is based solely on external economies of urbanization; however, it is an important component of agglomeration economies, theorized as a fundamental determinant of regional growth. ${ }^{6}$ Thus, these groups could be part of a regional development strategy. Yet as input-output specialists know well, inputoutput data alone do not account for externalities and do not account for where industries are located. ${ }^{7}$

Third, use of the proposed criteria alone may not be sufficient for judging the worth of one technique against another; however, in our view, they provide analysts with an important first step to narrow the range of choice among methods.

The criteria for assessing grouping methods are based on three questions. First, by definition, intra-group interindustrial linkages should be strong. To what extent do the results of a method adhere to the definition? Second, since the distribution of resources worldwide is uneven, each economy produces at least one good or service more efficiently than it does others. The production structures and output distribution patterns reflect such activity. To what extent does a method preserve these input and output patterns? If it does not, then analysts should seriously question whether the composition of the clusters reflects the interindustrial structure of the economy. Third, even if the first two criteria are satisfied, does a method have a questionable mathematical or statistical property? If so, then analysts cannot have much confidence in the method without further tests. Given these three questions, at a minimum any grouping method should: 1) reveal the sectors joined by the strongest linkages, 2) leave unchanged the structure of input purchases and the structure of sales patterns, and 3) conform to accepted statistical and mathematical properties.

The paper is divided into five remaining sections: methods, results, choice of method, suggestions for future research, and conclusion. The criteria are applied to two methods used in the study by Czamanski and $Q$. Ablas: Czamanski (1971) and Roepke, Adams, and Wiseman (1974). Unlike the study by Czamanski and Q. Ablas, however, the 
methods are applied to a single data base, the 1975 West Virginia input-output table (Loviscek et al., 1979), to facilitate comparison between the two methods. ${ }^{8}$

\section{Methods}

The two methods under examination are based on principal components analysis. They were chosen because 1) they can be applied readily to input-out data; 2) their properties are well-known to regional and urban researchers, and more so than alternatives such as graph theory (e.g., Campbell, 1975 and Slater 1977); and 3) O'hUallachain (1984) has argued forcefully that principal components methods can be a powerful tool for the identification of industrial groups. Although we would like to examine all of the aforementioned methods, the attempt would take the discussion beyond its focus. Nonetheless, the study shows how the three criteria can be used to determine the efficacy of each of the two grouping methods.

Our discussion is limited to the essentials of each method; detailed explanations can be found in the referenced articles. Briefly, principal components analysis is a data-reduction method that arranges variables (sectors) that account for a major portion of the variance in the data into a small number of groups. As applied in this study, the Czamanski (CZ) method begins with the derivation of conventional demand-constrained and supply-constrained coefficients, as follows:

(1). $a_{i j}\left(b_{i j}\right)=\frac{x_{i j}}{X_{j}\left(X_{i}\right)}$,

where $\quad a_{i j}\left(b_{i j}\right)=\begin{aligned} & \text { direct purchases (sales) } \\ & \text { by sector } i \text { from (to) }\end{aligned}$ sector $j$ per dollar of $j$ 's (i's) output,

$$
\begin{aligned}
\mathbf{x}_{\mathrm{ij}}= & \text { transactions flow from } \\
& \text { sector } \mathrm{i} \text { to sector } \mathrm{j} \text {, and } \\
\mathrm{X}_{\mathrm{j}}\left(\mathrm{X}_{\mathrm{i}}\right)= & \text { total gross output for } \\
& \text { sector } \mathrm{j}(\mathrm{i}) .
\end{aligned}
$$

The result is two $n \times n$ matrices, one for $a_{i j}$ 's and one for $b_{i j}$ 's. To measure how industries form a tightly-knit group, similarities in input and output patterns are determined by using zero-order correlation coefficients. The two $n \times n$ matrices are used to form an $n \times 4 n$ matrix of these correlation coefficients, as follows:

(2) $R=\left[r\left(a_{i k} \cdot a_{i l}\right), r\left(b_{k i} \cdot b_{l i}\right), r\left(a_{i k} \cdot b_{l i}\right), r\left(b_{k i} \cdot a_{i l}\right)\right]$.
The first submatrix deals with similarities in production structures between sectors $\mathbf{k}$ and $\mathrm{l}$; the second one measures similarities in output distribution channels. The third (fourth) one shows to what degree sector k's suppliers (customers) are sector 1's customers (suppliers).

The $\mathbf{R}$ matrix is reduced to an $\mathrm{n} \times \mathrm{n}$ intercorrelation matrix $\left(R_{\max }\right)$ by choosing the largest of the four coefficients associated with each cell of the four submatrices. Any one of the sectors with with either total interindustry sales or total interindustry purchases of zero is removed from $R_{\text {max }}$. Eigenvalues and eigenvectors are derived from the remaining coefficients. Division of each eigenvalue by the trace of $\mathbf{R}_{\max } \max$ indicates an "index of association." The larger the index, the more likely it is that certain elements, which correspond to sectors, in the associated eigenvectors comprise an industry group. These elements equal at least 0.20 here. Finally, each sector that both imports large (30 percent) amounts of inputs relative to total purchases, and exports large ( 30 percent) quantities of output relative to total sales, is removed from the industrial groups.

Like that of CZ, the method of Roepke et al. (RAW) attempts to measure similarities in input and in output patterns. It begins from a different data base than that of CZ, however. First, the authors make the conventional $n \times n$ matrix of transactions flows $\left(x_{i j}\right)$ symmetric so that the total transactions between two sectors do not reflect either an input or an output bias:

(3) $s_{i j}=x_{i j}+x_{j i}$

Correlation coefficients are then calculated from the $s_{i j}$ 's. Principal components are derived from the coefficients. All coefficients with eigenvalues exceeding unity are rotated by the varimax procedure, a widely accepted approach in principal components analysis, to aid in the interpretation of industrial groups. The groups are formed by finding the elements that exceed a selected cut-off level, in this case 0.40 .

The data are taken from the $197548 \times 48$ West Virginia input-output table. The first criterion, the identification of the strongest linkages, is implemented by forming twomember groups based on the six largest linkages as measured by either demandconstrained $\left(a_{i j}\right)$ or supply-constrained $\left(b_{i j}\right)$ coefficients: 
1. "all other" finance and insurance (37) and medical and legal services (39), $a_{i j}=0.42$

2. nonbuilding contractors (7) and petro$\operatorname{leum}(18), b_{i j}=0.33$

3 . insurance (35) and "all other" finance and insurance (37), $b_{i j}=0.28$

4. coal mining - underground (2) and logging and sawmills (14), $b_{i j}=0.27$

5. agriculture (1) and food and kindreddairy (10), $a_{i j}=0.24$

6. building contractors $(6)$ and special trade contractors $(8), a_{i j}=0.22$

Although the choice of six linkages is arbitrary, it seems reasonable that, to satisfy the first criterion, these linkages should be part of industrial groups generated by any method. The choice of the number of such linkages, however, will vary directly with the size and diversification of the industrial base and with the level of disaggregation in the input-output table. We emphasize, however, that the twomember groups are not the industrial groups that researchers have in mind. Each of the six pairs of sectors, with a few exceptions, is thought to be part of a larger group. For example, Czamanski and Czamanski (1977, p. 100) discuss the identification of "partial complexes" in which "at least three industries must be present" and "no more than two industries may be missing."

\section{Results}

The CZ method and the RAW technique generated the results shown in Table 1 and Table 2, respectively. ${ }^{\circ}$ A fundamental issue deals with cut-off levels. Because principal components analysis is a data-reduction method, there are not any statistical criteria about the significance of components. The objective is to account for as much variance in the data as possible. Furthermore, a threshold value must be selected for linking sectors with components. In both of these situations, the use of judgment cannot be avoided. In the present study, the strategy was to include components until they contributed little to the total variance while searching for threshold values that equaled at least 0.20 for the $\mathbf{C Z}$

Table 1

Industrial Groups for West Virginia Based on Czamanski's Method

1. Apparel and accessories (13)

Other finance and insurance (37)*

Medical and legal services (39)*

Gas companies (47)

2. Agriculture (1)*

Contractors-building (6)

Contractors-nonbuilding (7)

Food and kindred-meat (9)

Food and kindred-dairy (10)*

Food and kindred-beverage (12)

Logging and sawmills (14)

Educational services (40)

Water and sanitary services (48)

3. Food and kindred-dairy (10)

Food and kindred-bakery (11)

Food and kindred-beverage (12)

All other transportation (44)

Electric companies (46)

4. Contractors-building (6)

Contractors-nonbuilding (7)

Furniture (15)

Chemicals (17)

Stone and clay products (20)

Instruments (26)

Gas companies (47)
5. Coal mining-strip (3)

Logging and sawmills (14)

Furniture (15)

Fabricated metal (22)

Machinery (23)

Electrical machinery (24)

Transportation equipment (25)

Electric companies (46)

6. Coal mining-strip (3)

Printing and publishing (16)

Chemicals (17)

Petroleum (18)

All other manufacturing (27)

All other retail (32)

Insurance (35)

Real estate (36)

Railroads (42)

7. Food and kindred-bakery (11)

Primary metal (21)

Fabricated metal (22)

Machinery (23)

Hotels (38)

All other services (41)

Trucking and warehousing (43) 
Table 2

Industrial Groups for West Virginia Based on RAW's Method

1. Apparel and accessories (13)

Other finance and insurance (37)*

Medical and legal services (39)*

2. Agriculture (1)*

Food and kindred-meat (9)

Food and kindred-dairy (10)*

3. All other mining (5)

Contractors-building (7)*

Petroleum (18)*

Stone and clay products (20)

4. Logging and sawmills (14)

Furniture (15)

5. Petroleum and natural gas (4)

Chemicals (17)

Instruments (26)

All other manufacturing (27)

Railroads (42)

Gas companies (47)
6. Fabricated metal (22)

Machinery (23)

Electrical machinery (24)

Transportation equipment (25)

All other transportation (44)

7. Coal mining-underground (2)

Coal mining-strip (3)

8. Printing and publishing (16)

Retail food (30)

All other retail (32)

Real estate (36)

9. All other retail (32)

Banking (33)

Other finance (34)

Real estate (36)

Hotels (38)

Educational services (40)

All other services (41)

Communications (45)

(*Sectors with strongest linkages)

method and at least 0.40 for the RAW technique. The seven groups in Table 1 accounted for 74 percent of the total variance in the interindustrial data. More than this was desired, but additional components each accounted for about 2 percent additional variance and the distinction among components became increasingly blurred. As evidence of the latter point, 13 sectors are in more than one group. There were no major problems with the nine groups in Table 2. They accounted for 84 percent of the variance.

Comparatively, the results between the two methods appear different. For instance, the CZ approach grouped the 48 sectors into seven components, comprising a total of 49 sectors. The nine groups of the RAW method are comprised of 37 sectors. As mentioned, 13 sectors are in more than one group in Table 1, quite different from that in Table 2 where only two sectors repeat themselves. Morever, the $\mathrm{CZ}$ method produced a relatively larger number of manufacturing sectors and a relatively smaller number of service sectors than did the RAW technique. Of the 50 sectors in Table 1, 17 (34 percent) specialize in services and 25 (50 percent) are part of manufacturing, metal and nonmetal. In contrast, of the 37 sectors in Table 2,
16 (43 percent) deal with services and 15 (40 percent) are in manufacturing. In particular, the RAW method produced an eight-member group comprised solely of service industries (i.e., the ninth group). None of the seven groups in Table 1, however, resembles this group. All of these observations support our contention that practitioners need criteria to help them choose one method over others.

\section{First Criterion}

The CZ method produced groups that contain only two of the six strongest linkages; the RAW approach, only three of the six. Both revealed the strongest linkage (sectors 37 and 39). Both also identified the agriculture-food linkage (sectors 1 and 10). Why more of these linkages were not produced, however, is not clear. This could be due to the data, the manipulation of the data (e.g., using correlation coefficients) prior to use of the algorithms, or the operation of the algorithms. Further, the results showed that neither method generated all 11 sectors that comprise the strongest linkages (sector 37 is included twice). The CZ method produced nine of them while the RAW technique generated eight. Omitted in the 
former are coal mining-underground (2) and special trade contractors (8). Left out in the latter are insurance (35), contractors-building (6), and special trade contractors (8). In light of this information, one can question the composition of clusters produced by both methods. Moreover, neither input nor output patterns indicate why apparel and accessories (13)-produced by both methods-should be part of the industrial groups; more than 96 percent of its gross output is delivered to final demand. Similarly, the largest coefficient associated with educational services $(40)$ is less than two percent of total purchases. Likewise, the largest coefficient associated with hotels (38) is less than two percent of total sales. All of these points suggest that some of the industrial groups in Tables 1 and 2 do not fit the definition of an industrial group. This raises questions about the efficacy of the two methods.

\section{Second Criterion}

The second criterion, which requires that the input and output structures remain unchanged, is satisfied by the CZ but not the RAW method. The CZ method is based on direct input and direct sales coefficients. Since correlation coefficients derived from them are relative measures, it is safe to say that the method does not distort basic input and sales patterns. Some analysts might object to use of a symmetric matrix because it hides whether a linkage is either demand-constrained or supplyconstrained. This, however, is easily overcome by referring to the input and sales coefficients. Further, a strength of the $\mathrm{CZ}$ method is that it attempts to measure interindustry association in four ways, not only two, beginning with basic demand-constrained and supplyconstrained coefficients. These four measures of association give information on vertical interindustrial relationships-those that result from successive stages of production-and complementary relationships-those that result from mutual interdependence. Together, both of these relationships can be an important source of agglomeration phenomena (Tybout and Mattila, 1977).

In the RAW technique, it is not clear why a transactions table should be made symmetric. The authors assert that their interest lies more in total interindustry transactions than in whether linkages are either demand-constrained or supply-constrained. In our view, there are at least two objections to this approach. First, why not simply apply the method to the original, non-symmetric transactions matrix? As a measure of social accounting, these data represent the basis for developing fixed proportions production relationships. By using a symmetric matrix, RAW has upset the foundation for measurements of production structures and sales patterns. To illustrate, if the RAW technique is applied to unadjusted transactions data, then some differences are produced in industry groups compared to those in Table 2. For example, primary metals (21) produced one of the three largest outputs in 1975. This sector is not a member of any group in Table 2, but now forms a group with the coal mining sectors (2 and 3 ) and electric companies (46). A two-member group-eating and drinking establishments (28) and trucking and warehousing (43)-is generated from the nonsymmetric matrix but not from the symmetric one. The same is true for a four-member group-"all other" mining (5), contractorsbuilding (6), special trade contractors (8), and "all other" manufacturing (27). Second, and related to the first point, using a symmetric transactions flows matrix makes it impossible to determine accurately whether a linkage is demand-constrained or supply-constrained. Therefore, fundamental information on economic behavior is lost. For instance, sector i might have sold relatively large amounts of output to sector $j$. Sector $j$, however, might have sold nothing to sector $i$. After transposed and original flows are summed, however, sector $\mathrm{j}$ sold the same amount to sector $\mathrm{i}$ as $\mathrm{i}$ did to j. It is now impossible to tell who has sold to whom. Note, however, that the same cannot be said about the $\mathrm{CZ}$ method.

\section{Third Criterion}

To illustrate the use of the third criterion, which is concerned with the statistical and mathematical properties of a method, Bergsman et al. $(1972,1975)$ and Latham (1976) correlated employment data across industries to measure the spatial association of industries. Czamanski (1977), however, has criticized their application of correlation coefficients because the distribution of spatial phenomena tends to be highly skewed. Thus, linear correlation coef- 
ficients are unreliable measurements in this context. Moreover, transformation of the variables (e.g., dividing the variables by an area's population) is not likely to provide the normal bivariate populations.

With respect to the $\mathrm{CZ}$ technique, it violates the third criterion in the use of the $n \times n$ symmetric intercorrelation $\left(\mathbf{R}_{\max }\right)$. A symmetric matrix only guarantees that eigenvalues are real; it does not guarantee that they are positive. Yet all of the eigenvalues must be positive for the matrix to be positive-definite (Goult, 1978 , pp. 76-77). If the matrix is not positivedefinite, then the relationship between the eigenvalues and the eigenvectors is not unique; that is, more than one eigenvector may be associated with an eigenvalue. Recall that the $\mathrm{CZ}$ method uses eigenvalues to determine an "index of association" for each industrial group, which is found by searching for relatively large elements in an eigenvector. The $\mathbf{R}_{\max }$ matrix from which the eigenvectors are derived must be positive-definite to guarantee a unique relationship between an index of association and an industrial group. In other words, all 48 eigenvalues of the $48 \times 48 R_{\max }$ matrix must be positive; otherwise, the same indices of association used to obtain the results in Table 1 can lead to a different set of industrial groups. In conventional principal components analysis, the objective of the $\mathrm{CZ}$ method can be stated as follows:

(4) $\max a_{1} \mathrm{TX}^{\mathrm{T} X a_{1}}=a_{1} \mathrm{~T}_{\max } \mathrm{a}_{1}$

(5) s.t. $a_{1} \mathrm{~T}_{a_{1}}=1$,

where $a_{1}=$ first eigenvector associated with the first eigenvalue,

$\mathrm{X}=\mathrm{n} \times \mathrm{n}$ matrix of interindustry data, and

$\mathrm{T}=$ transpose.

With conventional principal components (i.e., no $\mathrm{R}_{\max }$ ), the product $\mathrm{X}^{\mathrm{T}} \mathrm{X}$ yields positive eigenvalues, and therefore the matrix is positive-definite (Bolch and Huang, 1974, pp. 238-243). The same cannot be said, however, in this application of $R_{\max }$. Of the 48 eigenvalues, 17 are negative. Therefore, $R_{\max }$ is not positive-definite and the relationship between the indices of association and the industrial groups is not unique. Moreover, a negative index of association does not make economic sense. We emphasize, however, that this does not invalidate the $\mathrm{CZ}$ method because it is difficult to generalize accurately from the specific application. Nonetheless, the results suggest that analysts be especially cautious when using the method.

The CZ method attempts to show that industries can be linked in four ways. As mentioned earlier, this is an important feature of the method, because it attempts to measure vertical and complementary interindustrial relationships. Of the four submatrices, however, the fourth one $\left[r\left(b_{k i} \cdot a_{i l}\right)\right]$ adds no new information on interindustrial linkages because it is simply the transpose of the third one $\left[r\left(a_{i k} \cdot b_{l i}\right)\right]$. Removal of the fourth submatrix, however, will yield a non-symmetric matrix, the mathematical properties of which are not known as well as those of the symmetric matrix (Goult, 1978).

None of the problems mentioned above affects the RAW method. First, as pointed out, the authors used a different measure of linkages than that used in the $\mathrm{CZ}$ technique. Second, because the RAW method involves a conventional application of principal components analysis (i.e., it does not use anything resembling an $\mathbf{R}_{\max }$ matrix), all of the eigenvalues are positive, indicating that the data matrix from which the components are generated is positive-definite.

\section{Choice of Method}

Choosing between the two methods is not easy in this study because neither one satisfies all three criteria. Nonetheless, after examining the weaknesses of each method, we think the RAW technique is to be preferred for two reasons. First, unlike the $\mathrm{CZ}$ method, it does not violate the third criterion. Second, replacing the symmetric matrix with a simple combination (e.g., an unweighted average) of demand- and supply-constrained coefficients would satisfy the second criterion and maybe the first. Unfortunately, it is not clear how the CZ method could be changed to satisfy the third criterion without eliminating the $n \times 4 n$ matrix, which is a special feature of the approach. Moreover, if the $n \times 4 n$ matrix is transformed into a non-symmetric matrix, there is a reasonable chance that some of the eigenvalues of the matrix could be complex. If that happens, the indices of association become difficult to interpret. As a caveat, though, we emphasize that our choice is based 
on the results generated only from the data used in this study. Because of the inductive nature of this area, we cannot rule out the possibility of a different choice when different data are used.

\section{Directions for Future Research}

Rather than propose a method that overcomes the problems of the two approaches, we recommend that analysts look carefully at the data base in their future research. As pointed out in the study by Yotopoulos and Nugent, the diversity of results might be due more to the choice of data base than to the choice of method. Specifically, they should examine: 1) demand-constrained coefficients $\left(a_{i j}{ }^{\prime} s\right)$ and supply-constrained coefficients $\left(b_{i j}\right.$ 's) and 2$) a$ Leontief inverse for each set of coefficients. With respect to the first point, a review of the literature indicates that not all of the methods deal with both coefficients. For example, the techniques of Roepke et al (1974), Blin and Cohen (1977), and Slater (1977) do not. ${ }^{10}$ In particular, Blin and Cohen used only demand-constrained coefficients. There is no reason to assume that industrial bases are dominated by industries with a demand orientation; that is, a relatively large amount of inputs is bought from industries within the region. From the viewpoint of industrial location theory, industrial bases that produce large amounts of "weight-losing" products are likely to have strong forward, or supply, effects on their customers. In such instances, industrial groups generated solely from demand-constrained coefficients might not accurately represent the interindustrial structure. Therefore, attempts must be made to incorporate suppy-constrained behavior into the linkages. The methods that use both coefficients, however, have not adequately dealt with the issue of how a matrix of demandconstrained coefficients should be combined with one of supply-constrained coefficients. As explained, the CZ method combines the coefficients into $R_{\max }$, which is superficially pleasing. But, as pointed out, $R_{\max }$ might not have desirable mathematical properties. Streit (1969) and Latham (1976) take the average of four coefficients. Taking an average, however, assumes that the strength of demandconstrained behavior equals that of supplyconstrained behavior. The uneven distribution of inputs across regions suggests that the strengths are not equal. This suggests the use of a weighted average of the coefficients rather than a simple average (Loviscek, 1982).

Perhaps a major reason why more work has not been done on integrating demandconstrained coefficients with supply-constrained coefficients deals with a theory of sales patterns. Presently, none exists. ${ }^{11}$ This means that, unlike conventional input coefficients linked to production theory, sales coefficients cannot be linked to a theory. Thus, a "fixed sales" hypothesis might measure sector i's ability to satisfy sector $\mathrm{j}$ 's demand for an input, but it is deficient as a tool for explaining behavior. Undoubtedly, more work is needed on a theory of sales patterns.

Few analysts have dealt with whether the use of direct coefficients $\left(a_{i j}\right.$ and $\left.b_{i j}\right)$ are to be preferred over the use of Leontief inverses each for demand-constrained coefficients and for supply-constrained coefficients. Blin and Cohen (1977, p. 89$)$ demonstrated that industrial groups produced from the demandconstrained inverse for the United States were "quite different from those based on direct technological similarity." Loviscek (1982) applied principal component analysis to a combination of demand-constrained and supply constrained Leontief inverse coefficients derived from the same data as that used here. The groups so generated were similar to those in Table 2. Moreover, examination of the results and the method shows that all six of the strongest linkages were produced without distorting interindustrial linkages. This evidence suggests that choice of a method might not be as important in generating industrial groups as choice of the data base.

\section{Conclusion}

This paper attempts to demonstrate how three criteria can be used to assess the efficacy of methods designed to bring order to interindustry data. It is our contention that any grouping method should satisfy at least three criteria: 1) reveal the strongest interindustrial linkages, 2) preserve interindustry buying and selling patterns, and 3) conform to accepted mathematical and statistical properties. The criteria are applied to the results generated by two principal components approaches. We show that the efficacy of each method can be 
questioned; however, we conclude that the RAW method is to be preferred if it is modified. Rather than propose a new method, we suggest that different measurements of interindustrial linkages be used. More attention needs to be given supply-constrained coefficients, a combination of demand-constrained and supply-constrained coefficients, and Leontief inverses. It could be that choice of interindustrial linkage measurements may be more important in the generation of industrial groups than choice of method.

\section{FOOTNOTES}

'Latham (1976) made what, at first, seemed a compelling argument against the use of graph theory and principal components analysis. Czamanski (1977), however, showed that Latham's argument has several weaknesses.

'Industrial groups need not dominate economic activity. They provide insight into the interindustrial structure of an economic base.

This, of course, presumes that the third question raised in this study has been answered.

-Specific techniques of exploratory data analysis can be found in Anderberg (1973) and Tukey (1977).

'If the number of industrial groups is large (e.g., 25), then some chi-square based measures can be used, providing that they conform to particular probability distributions. For more information, see Anderberg (1973), pp. 75-80.

-An industrial group whose members are located close to each other has been called a "complex" (Czamanski and Czamanski, 1977). For more information on the relationship between external economies and agglomeration phenomena, see Richardson (1979), pp. 61-63.

'One can argue that regional input-output transactions for small regions reflect similarities in locational patterns of industries.

Czamanski and Q. Ablas only summarized the results of previous studies. They did not apply the methods to a single data base as part of a test of the efficacy of each method.

Two-member groups, such as those in Table 2, may not be uncommon in less-developed areas. If per capital income is used as a gauge for the extent of economic development, then West Virginia is certainly lessdeveloped. Its per capita income ranking in 1975 placed it in the lowest quartile among the 50 states. For further details, see U.S. Department of Commerce, Survey of Cur rent business, August (1977), p. 17.

'Slater's method is unique. He used what is called a "biproportional" approach for simultaneously adjusting the rows and columns of a transactions table so that the flows are in relative terms. The adjusted flows, however, are not the same as input and sales coefficients.

"For further details on this subject in regional analysis, see Giarratani (1980).

\section{REFERENCES}

Anderberg, Michael. Cluster Analysis for Applications. New York: Academic Press (1973).

Bergaman, J., P. Greenston, and R. Healy. "The Agglo- meration Process in Urban Growth." Urban Studies. 9(1972). 263-288.

Bergsman, J., P. Greenston, and R. Healy "A Classification of Economic Activities Based on Location Patterns." Journal of Urban Economics. 2 (1975). 1-28.

Blin,-Jean M. and Claude Cohen. "Clustering and Acreregetion in Input-Output Systems." Review of Economics and Statistics. 54 (1977). 376-380.

Bolch, Ben and Cliff Huang. Multivariate Statistical Methods For Business and Economics. Englewood Cliffs, NJ: Prentice-Hall, Inc., 1974.

Boucher, Michel. "Some Further Results on the Linkage Hypothesis." Quarterly Joumal of Economics. 90 (1976). 313-318.

Campbell, John. "Application of Graph Theoretic Analyris to Interindustry Relationships." Joumal of Regional Science and Urban Economics. 5 (1975). 91-106.

Czamanski, Daniel and Stan Czamanski. "Industrial Complexes: Their Typology, Structure, and Relation to Economic Development." Papers and Proceedings of the Regional Science Association. 38 (1977). 93-111.

Czamanski, Stan. "Needless Complexity in the Identification of Industrial Complexes: A Comment." Joumal of Regional Science. 17 (1977). 455-458.

Czamanski, Stan and Luiz de Q. Ablas. "Identification of Industrial Clusters and Complexes: A Comparison of Methods for Findings." Urban Studies. 38 (1979). 61-80.

Giarratani, Frank. "The Scientific Basis for Explanation in Regional Analysis." Papers and Proceedings of the Regional Science Association. 45 (1980) 185-196.

Goult, R. J. Applied Linear Algebra. New York: John Wiley \& Sons, Inc., 1978.

Harrigan, F. J. "The Relationship Between Industrial and Geographical Linkages: A Case Study of the United Kingdom." Journal of Regional Science. 22 (1982). 19-31.

Jones, Leroy P. “The Measurement of Hirschmanian Linkages." Quarterly Joumal of Economics. 90 (1976). 323-333.

Latham, William R. "Needless Complexity in the Identification of Industrial Complexes." Joumal of Regional Science. 16 (1976). 45-55.

Laumas, Prem S. "The Weighting Problem in Testing the Linkage Hypothesis." Quarterly Joumal of Economics. 90 (1976). 308-312.

Lodh, E. K. and J. S. Lewis. "Identification of Industrin Complexes From Input-Output Tables of Canada and the U.S.A.: Some Empirical Tests." Empirical Economics. 1 (1975). 53-80.

Loviscek, A. L. "The Generation of Industry Groups From Input-Output Data: A Comparison of Four Methods." Environment and Planning A. 16 (1984). 779-791.

Loviscek, Anthony L. "Industrial Cluster Analysis: Backward or Forward Linkages?" Annals of Regional Science. 16 (1982). 41-53.

Loviscek, Anthony L., Randy E. Holliday, Lucinde A. Robinson, and Melissa A. Wolford. The West Virginic Input-Output Study: Modeling a Regional Economy. Morgantown, WV: West Virginia University Prese, 1979.

Masser, I, and P. J. Brown. "Hierarchical Aggregation Procedures for Interaction Data." Environment and 
Planning A. 7 (1975). 509-523.

Masser, I. and J. Scheurwater. "Functional Regionalization of Interaction Data: An Evaluation of Some Suggested Strategies." Environment and Planning A. 12 (1980). 1357-1382.

O'hUalla'chain, Breanda'n. "The Identification of Industrial Complexes." Annals of the Association of American Geographers. 74 (1984). 420-436.

Richardson, Harry W. Regional Economics. Urbana, IL: University of Illinois Press, 1979.

Riedel, James. "A Balanced-Growth Version of the Linkage Hypothesis: A Comment." Quarterly Journal of Economics. 90 (1976). 319-322.

Roepke, Howard, David Adams, and Robert Wiseman. "A New Approach to the Identification of Industrial Complexes Using Input-Output Data." Journal of Regional
Science. 14 (1974). 15-29.

Slater, P. B. "The Determination of Groups of Functionally Integrated Industries in the United States Using a 1967 Interindustry Flow Table." Empirical Economics. 2 (1977). 1-9.

Streit, M. E. "Spatial Association and Economic Linkages Between Industries." Journal of Regional Science. 9 (1969). 177-193.

Tukey, John. Exploratory Data Analysis. Reading, MA: Addison-Wesley Publishing Company, 1977.

Tybout, Richard A. and John M. Mattila. "Agglomeration of Manufacturing in Detroit." Journal of Regional Science. 17 (1977). 1-16.

Yotopoulos, Pan A. and Jeffrey Nugent. "A BalancedGrowth Version of the Linkage Hypothesis: A Test." Quarterly Journal of Economics. 87 (1973). 157-171. 